\title{
The Effects of Shot Peening on Short Crack Growth Rate and Resulting Low Cycle Fatigue Behaviour in a Low Pressure Turbine Blade Material
}

\author{
He, B. ${ }^{* 1}$; Soady, K.A. ${ }^{1,2}$; Mellor, B.G. ${ }^{1}$; Morris, A. ${ }^{2}$; Reed, P.A.S. ${ }^{1}$ \\ 1. Materials Research Group, Engineering and the Environment, University of Southampton, Highfield, \\ Southampton, SO17 1BJ, UK \\ 2. E.ON New Build \& Technology Ltd., Ratcliffe on Soar, Nottingham, NG11 0EE, UK
}

\begin{abstract}
The effect of shot peening on subsequent low cycle fatigue behaviour of a representative low pressure (LP) steam turbine blade material has been investigated in bend test samples. An analysis of the short fatigue crack growth behaviour has been conducted. For samples with no stress concentration feature shot peening was found to have a more evident beneficial effect at lower strain levels than at higher strain levels whereas for samples with a stress concentration feature, the beneficial effect was retained even at higher strain levels.

Pre-existing cracks were observed on the shot peened surface, which started to grow at $10 \sim 25 \%$ of fatigue life in the low cycle fatigue regime. The crack propagation rate was slower than that observed in the ground sample suggesting that the shot peening process delayed crack propagation. This improvement in fatigue life has been attributed to the significant slowing of small cracks while growing through surface regions of significant compressive residual stresses and local work hardening developed by the shot peening process. Once cracks in the notch root have penetrated this region in the depth direction, faster crack growth rates, similar to those observed in the ground case, were seen.
\end{abstract}

Key words: Low cycle fatigue, Shot peening, Residual stress, Short crack initiation and propagation, Ferritic heat resisting steel

\section{Introduction}

Industrial steam turbine components are safety critical parts which are subjected to low cycle fatigue (LCF) stresses of thermal and mechanical origin during start up and shut down. Nondestructive testing (NDT) is carried out during routine maintenance inspections approximately every twelve years in order to locate and size any defects, especially at the fir tree blade disc interfaces where several severe stress concentrations exist. A range of refurbishment activities are then undertaken to ensure the integrity of the turbine in the next operational cycle. Such major outages typically last 8-12 weeks and for a $500 \mathrm{MW}$ unit the cost in lost generation is $>£$ M. The development of life assessment methods which can justify deferring invasive inspections and reducing the scope of maintenance works thus has the potential to save operators considerable amounts.

A damage tolerant fatigue lifing approach is typically applied to such components to determine the maximum number of future start up and shut down operations as part of a component repair and replacement schedule. These assessments are vital to the timely repair 
and replacement of assets, ensuring that safety margins are maintained in the most cost effective manner. Lifing simulations are required to allow prediction of lifetime scatter and hence allow risk assessments to be performed for a wide range of materials, loading geometries and surface conditions. Blade disc interfaces are typically shot peened in an attempt to reduce their susceptibility to fatigue, however, the resulting benefits are considered as conservatism in the life assessment model; their inclusion would allow this conservatism to be reduced whilst maintaining safety margins.

Shot peening is a well-known surface treatment process typically applied to components containing regions of stress concentration (such as steam turbine blade disc interfaces) to improve their fatigue resistance. By bombarding a component with small spherical shot of a hard material at a relatively high velocity, near surface plastic flow means the surface material is strain hardened. The magnitude of the plastic strain induced decreases with depth until at a certain depth the material only deforms elastically. These elastic regions tend to recover to the unloaded state, unlike the plastically deformed regions which retain some deformation; the continuity condition thus requires the development of compressive residual stresses in the near surface region.

The resulting effect on fatigue life is a combination of these three surface features (roughness, strain hardening and compressive residual stresses) and service loading conditions; a recent review $^{1}$ details these interactions extensively and only a brief introduction to the most pertinent aspects of the present investigation is given in this work.

Although the plastic deformation results in increased surface roughness which is generally considered to reduce initiation time as a result of the presence of micro stress concentrators, ${ }^{2-}$ ${ }^{4}$ the beneficial effects of the strain hardening and the compressive residual stresses usually dominate any detrimental surface roughness effects ${ }^{5}$ and the overall effect of shot peening is to increase fatigue life with both delayed initiation ${ }^{6}$ and reduced crack propagation rates reported. ${ }^{4,6,7}$ Strain hardening increases the yield stress in the material near the surface and hence lower plastic strain amplitudes are reached under stress controlled cycling, ${ }^{8}$ tending to increase initiation life. ${ }^{4,9}$ Compressive residual stresses superpose with applied tensile stresses to reduce the mean stress, ${ }^{10,11}$ the major beneficial effect being a reduction in crack propagation rates $;{ }^{9}$ indeed it has been shown that non-propagating cracks may exist, ${ }^{12}$ the depth of which typically coincides with the depth of the compressive residual stress layer. De los Rios et al. ${ }^{6}$ also indicate that crack arrest can occur; indeed they report that small cracks initiate quickly at the edges of dimples resulting from shot peening a $0.4 \% \mathrm{C}$ steel but that they arrest for a period of time before propagating. It was suggested that this was when the residual stresses had relaxed sufficiently as to allow crack propagation to begin, but no evidence was available to support this.

It is also still unclear as to the relative contributions of the two beneficial effects to the improvement in fatigue life. ${ }^{11}$ Attempts to unpick these effects have been made by both Wagner, ${ }^{9}$ who showed that crack initiation was retarded predominantly by strain hardening and propagation by compressive residual stresses and Eleiche et al. ${ }^{13}$ whose work demonstrated that strain hardening made a significant contribution to the improvement in 
endurance limit in a high strength martensitic steel. However, both these works can be considered to be in the stress controlled regime, to the best of the authors' knowledge there is no similar attempt to separate the effects in the strain controlled regime.

Short cracks can be defined in several different ways, the most important to the present work being if the crack length is comparable to the scale of local plasticity, eg. a crack which is in the plastic zone of a notch, or indeed in the region of material affected by shot peening plasticity, or if the crack length is physically small (eg. $\leq 0.5 \sim 1 \mathrm{~mm}){ }^{14}$ Typically short cracks propagate more quickly than long cracks under the same stress intensity factor range, $\Delta K$ and short cracks emanating from notches propagate faster still when the notch plastic zone engulfs the short crack region. ${ }^{15}$ In such situations, linear elastic fracture mechanics (LEFM) is not sufficient to explain the propagation behaviour and there are attendant problems in lifing components containing such short cracks, for example turbine blades and discs; ${ }^{14,16}$ these problems are made more complex by the addition of the shot peening process. There have been some reports in the literature of short crack behaviour in shot peened materials; given the typical total depths of the compressive residual stress profile are in the range 200$500 \mu \mathrm{m}$, the effect of shot peening on the short crack growth regime is of great significance.

Mutoh et $a l .^{4}$ used a combination of replication and potential drop techniques to investigate the crack propagation rate as a function of $\Delta K$ in shot peened notched aluminium samples which were tested under a stress ratio of 0.1 in the elastic regime. In order to correlate the surface crack length, $2 c$, measured using replication techniques with the crack depth through the sample, $a$, some tests were interrupted at varying stages of life to show that the aspect ratio $a / c$ increased as $a$ increased before stabilising at a level lower than that in unpeened samples; this was thought to be dependent on surface geometrical features and compressive residual stresses. However, this change was not reported in the work of Gao and $\mathrm{Wu}{ }^{7}$ Mutoh et $a l^{4}$ also showed that the crack growth rate reduced with increasing $\Delta K$ until the crack length corresponded to the depth of the maximum residual stress after which the growth rate rapidly increased to a level corresponding to that of the unpeened samples. This reduction in short crack growth rate was also shown to be significant in aluminium samples by Gao and $\mathrm{Wu}^{7}$ and in steel samples by de los Rios et al.. ${ }^{6}$

Whilst the reduction in high cycle fatigue (HCF) life is well documented, ${ }^{13}$ the effect on LCF life is less clear given residual stresses may relax if further plastic strains are induced in the material during service reducing the plastic misfit which caused the compressive residual stresses. ${ }^{17-25}$ The extent of relaxation depends on factors such as the service temperature, the interaction between the residual and applied stress distribution in the specific component geometry of interest and the cyclic behaviour of the material in question. ${ }^{1,20,25}$ In considering the applied stress distributions and the cyclic material behaviour, it is important not to forget that the surface layers of the material have already undergone several load cycles and are strain hardened as a result of the shot peening process. As a result of these considerations, it would not be unreasonable to expect that short crack growth behaviour may change in shot peened materials under LCF conditions as compared to under HCF conditions. 
The present study is a part of a larger project on developing the shot peened LP steam turbine blade lifing methodology in order to consider the influence of residual stresses and strain hardening. The key objectives of the present work are twofold, the first is to quantify the effect of shot peening (in samples with or without a stress concentration feature) on LCF life. Samples made of a representative steam turbine blade material are loaded to excess of yield in a bend configuration which is deemed representative of service conditions (for example during start up, shut down and overspeed tests). The observed behaviour is linked to the residual stress and applied stress distributions and associated relaxation behaviour that has previously been reported in this system, this enables us to assess the efficacy of shot peening regions containing stress concentration features which are subjected to LCF loading. ${ }^{25}$

The second objective is to assess fatigue crack initiation and propagation behaviour in ground and shot peened notched samples tested under conditions of local notch plasticity. Clearly in order to be able to predict the fatigue life of a shot peened component from local stress and strain or fracture mechanics parameters resulting from a finite element model, it is essential to understand the micromechanisms by which the crack first initiates in and then propagates through the affected layer. Furthermore, before implementing a damage tolerant fatigue lifing model, it must be validated for samples of relatively simple geometry; with remnant life after the initiation of a crack which could be detected by NDT the most important parameter, the dataset generated as a result of this work provides the means of testing such models.

\section{Experimental Methodology}

FV448 is an $11 \%$ Cr-Mo-V tempered martensitic steel, which has been austenitised at 1150 ${ }^{\circ} \mathrm{C}$, oil quenched, and then tempered at $650{ }^{\circ} \mathrm{C}{ }^{26}$. Table 1 indicates the composition of the steel evaluated in this work. The fatigue performance of ground (surface roughness $\mathrm{Ra}=$ $0.652 \pm 0.0724 \mu \mathrm{m}$, along the direction transverse to loading direction) and shot-peened samples (surface roughness $\mathrm{Ra}=3.39 \pm 1.06 \mu \mathrm{m}$ ) have been compared. In this study, one shot peening condition in particular has been considered: The Almen intensity was $13 \mathrm{~A}$; this was achieved using shot diameter $=0.58 \mathrm{~mm}$, shot hardness $=45-52 \mathrm{HRC}$ and shot velocity $=$ $57 \mathrm{~ms}^{-1}$. The coverage was $200 \%$. The residual stress distributions resulting from both the grinding and the shot peening processes have been reported previously. ${ }^{25}$

The fatigue behaviour of this representative turbine blade material has been evaluated both in the presence of a stress concentration feature, a U-notch bend specimen, (the S-N data for which has been reported elsewhere ${ }^{25}$ ) and in a smooth plain bend bar (PBB) configuration. Both specimen types and their test geometries are shown in Figure 1; specimen breadth was 8 $\mathrm{mm}$.

The U-notch geometry was chosen to simulate the fir tree root geometry of the turbine blade and has an elastic stress concentration factor, $K_{t}$, calculated using an elastic FE analysis of 1.6 .

Fatigue testing was carried out at a frequency of $20 \mathrm{~Hz}$ using a sinusoidal waveform and a load ratio $\mathrm{R}=0.1$, using an Instron 8501 servo hydraulic machine at room temperature. Since the maximum service temperature of low pressure (LP) turbines $\left(250^{\circ} \mathrm{C}\right)$ is outside the creep 
regime for this material, consideration of creep-fatigue interaction is not required in the life assessment process for these components and room temperature behaviour is considered representative for life assessment approach development. Samples were tested until failure and the stress and strain levels in the two different geometries assessed by construction of an Abaqus finite element model. A quarter model was employed relying on specimen symmetry and an elastic-plastic material model employing isotropic hardening conditions based on true stress-strain data taken from (monotonic) tensile testing was implemented. Elements were full integration 20 node quadratic hexahedral C3D20 type and were $0.01 \mathrm{~mm}$ in depth adjacent to the surface loaded in tension. A representation of the first loading cycle was obtained through sequential static analysis of stress and strain distributions under maximum, minimum and no load.

To assess the effect of the shot peening process on crack growth behaviour, a replication technique was used to monitor crack initiation and short crack growth on the shot peened and ground U-notched samples. A replica of the U-notch top surface was taken every 1000 cycles until a crack was first clearly observed, and then every 500 cycles until failure. Initiation points were identified and crack growth rates of surface cracks were calculated from the replica record. The replica material used in the current project was RepliSet-F5 (Struers Ltd). Replicas taken from both ground and shot peened samples were analysed using an Olympus BX51 polarized light microscope and cracks images were stitched together by FIJI Image software so as to present an overview of these cracks. Measurements of the crack length from the digital images of the replica record were performed using Image-Pro Plus software from hand tracing along the cracks length, which makes the explicit measurement of these zigzag crack paths possible. During calculation, a calibration file automatically transforms pixel values to lengths in micron. Both the real surface crack length $2 c$ and projected crack lengths $2 c_{\text {proj }}$ were measured. In the present research, half surface crack length $c$ was used to calculate crack growth rates applying the secant method:

$$
\frac{d c_{i}}{d N_{i}}=\frac{c_{i+1}-c_{i-1}}{N_{i+1}-N_{i-1}}
$$

Where $i$ is the datum taken at a particular replica interval during the fatigue process, $\mathrm{N}_{\mathrm{i}}$ is the number of fatigue cycles at that replica interval, and $c_{i}$ is crack length at $\mathrm{N}_{i}$ cycles. To compare the crack growth behaviour, both shot peened and ground samples were tested under a similar local strain range $\left(\Delta \varepsilon_{\mathrm{LE} 11}=1.1 \%\right)$, calculated in terms of the maximum tensile strain direction, for which residual stress data had previously been collected. Detailed fractographic analysis of the fracture surfaces and notch roots was also carried out in a JEOL JSM-T300 SEM, operating at an accelerating voltage of $15 \mathrm{kV}$.

\section{Results}

The microstructure was revealed by the use of Vilella's etch to be a tempered martensitic steel as shown in Figure 2. No evidence of significant amounts of MnS stringers have been found in this material. The $0.2 \%$ proof stress was found to be $806 \pm 6 \mathrm{MPa}^{25}$. 
It was noticed that the top surface of the plain bend bar samples developed a significant lip after shot peening (as illustrated in Figure 3) due to significant plastic deformation of the top surface resulting from the shot peening process. The strain-life plot for the plain bend bar samples is presented in Figure 4. True stress (S11) and strain (LE11) were determined at the notch surface in the direction of the maximum applied tensile fatigue load. Figure 4 therefore shows the lifetime as a function of the range of true strain at the notch strain. The fatigue samples are in the TL orientation, with the cracks growing in the longitudinal direction (the rolling direction), with the tensile axis along the transverse direction. It is noteworthy that the effects of shot peening are significantly improved if these lips are removed - as seemingly they have provided a significant stress concentration feature. The beneficial effects of shot peening (even when these top surface "lips" have not been removed which would be the service condition) are most evident for PBB samples at lower strain ranges (for example below yield) whereas at the higher strain ranges such as $1 \%$, significant yielding has occurred and the beneficial shot peening effect is negated.

If we now compare this behaviour with the strain life plot for the U-notch samples ${ }^{25}$ (also shown in Figure 3) it is clear that under the same local stress/strain (hot spot stress), notched samples exhibit a greater fatigue life than PBB samples. Furthermore, it is also evident that shot peening is still beneficial even at a strain range of $1 \%$ in this much more highly constrained system. Although a less dramatic benefit is seen at strain ranges above $\sim 1 \%$, the benefits are still significant.

The initiation and growth of cracks in the notch root for ground and shot-peened samples has been further evaluated from the replica record. By tracking back through the replicas taken throughout the fatigue life, it is possible to unambiguously identify the fatigue crack initiation sites on the surface and the crack growth history. The cracks reported in the present research are those that coalesced in the late stages of fatigue life and hence led to final failure. The interrupted replica tests are indicated by arrows in Figure 4. Four cracks were studied in detail in both the shot peened and ground samples, as illustrated in Figure 5 (a) and (b), respectively. The surface crack length, $c$, versus $N_{i} / N_{f}$ (fatigue lifetime fraction, where $N_{i}$ is the number of cycles at the replica interval and $N_{f}$ is total fatigue life) for the shot peened and ground U-notch samples are shown in Figure 6 (a) and (b), respectively; while the corresponding crack growth rates are plotted against crack length (in log-log form) in Figure 7(a) and (b).

In the shot peened case, it is noted that the observed crack length in the very early stages of fatigue life is not zero (for example, the total initiating crack length of crack B 1 is $51 \mu \mathrm{m}$, whilst it is $242 \mu \mathrm{m}$ for specimen crack B2 before any cyclic loading has occurred). This indicates that cracks seem to pre-exist on the shot peened surface. When $N_{i} / N f$ was $0.1 \sim 0.25$, these pre-initiated fatigue cracks started to grow but the crack lengths did not increase dramatically until around $80 \%$ of the total fatigue life, where crack coalescence occurred frequently and secondary cracks also began to grow. The crack growth behaviour in the ground samples (with little residual stress in the near surface layer ${ }^{25}$ ) was quite different. The cracks first appeared on the ground surface at around $50 \%$ of the fatigue life, after that, the
Formatted: Font color: Red Highlight 
cracks developed at a constant rate and accelerated near the end of fatigue life, when the main cracks coalesced, leading to failure. Compared to the shot peened case, crack coalescence in the ground sample occurred infrequently even near the end of fatigue life, partly because there were significantly less initiation sites during the fatigue process.

Given the highly plastic nature of deformation in the present case, $\Delta K$ levels have not been calculated, but given the expected strain range in the notch root (ignoring any local effects of work hardening or compensating residual stresses) the $d c / \mathrm{d} N$ versus $c$ data gives a reasonable comparison of crack growth rates under similar externally imposed stress states. Highly scattered crack growth rates are observed which is typical of short crack growth behaviour. It is noticeable that in the ground case the crack growth rates are fairly constant $(d c / \mathrm{d} N$ levels of between $1 \times 10^{-3}$ and $1 \times 10^{-5} \mathrm{~mm} \mathrm{cycle}^{-1}$ ) during the fatigue process, indicating that the relatively constant strain range rather than any $\Delta K$ level may be acting as the crack driving force. The crack growth rates of the cracks on the shot peened surface showed a wider range, generally increasing with crack length, and generally lower $d c / \mathrm{d} N$ values were observed: $\left(d c / \mathrm{d} N\right.$ levels of between $1 \times 10^{-7}$ and $1 \times 10^{-3} \mathrm{~mm}$ cycle $\left.^{-1}\right)$. Under similar externally applied local strain range conditions, the total fatigue life of the shot peened sample was 54504 cycles, while the ground sample had a life of 22816 cycles.

To make the difference in crack propagation behaviour more apparent, the crack morphologies of crack B1 (on the shot peened surface) and crack 4 (on the ground surface) at different fatigue stages are presented in Figure 8 (a) and Figure 9 (a), respectively. In Figure 8 (a), some cracks on the rough shot peened surface can be identified before the fatigue test. As the fatigue test continued, these 'pre-existing' cracks did not change length dramatically, as can be seen in Figure 6 (a). At around $80 \%$ of the fatigue life, cracks clearly propagated; after that crack coalescence frequently occurred and secondary cracks also began to grow, leading to a faster growth rate. At the end of fatigue life, the crack identified as crack B2 in Figure 8(a) coalesced with other main cracks, crack A and crack B1, and the sample then failed. As previously mentioned, the surface roughness induced by the shot peening process in this study is $\mathrm{Ra}=3.39 \pm 1.06 \mu \mathrm{m}$. Figure 8 (b) shows a crack which has initiated from a shot peened dimple on the notch surface; this would tend to support the viewpoint that the edges of the shot peening dimples act as stress concentrations with 'pre-existing cracks' (mentioned earlier) at the edges of shot peening dimples.

As shown in Figure 9(a), the crack propagation behaviour of the ground sample is different. There was no pre-existing crack and a fatigue crack appeared at about $50 \%$ of fatigue life. Once it had formed it propagated quickly along the grinding marks in the sample as shown in Figure 9(b).

\section{Discussion}

The total life of the notched samples is greater than that of the PBB samples when the strain range is determined using a hot spot approach; that is when the strain range is determined at the notch surface. This is considered to be a result of the different stress states between the two samples as illustrated in Figure 10: It can be seen that the very high stresses 
corresponding to plastic behaviour extend far deeper in the PBB than in the U-notched sample.

It was previously noted that for PBB samples containing no stress concentration feature, there was no benefit derived from shot peening (whether or not the top surface lips were removed) at the highest strain range of $1 \%$ at the notch surface. In contrast, it was noted that in the Unotched samples, the shot peening process remained beneficial in terms of fatigue life when the strain range was $1 \%$ at the notch surface.

This result can be explained by consideration of the relaxation of the residual stresses resulting from shot peening. Quasi-static residual stress relaxation can occur after just one fatigue cycle if the applied stress interacts with the residual stress in such a way as to cause yielding in material which had previously only been elastically deformed by the shot peening process. In this case, the plastic misfit which caused the presence of the compressive residual stresses may be reduced, although it should be noted that the work hardening effects would still be expected to remain.

The differing relative effect of shot peening at high strain ranges may be expected, given the applied stress distributions in the different geometries illustrated in Figure 10 (it is noted that although not considered in the present FE model, the local effect of work hardening from the shot peening may also be expected to affect the stress distribution). In a recent review, Soady ${ }^{1}$ concludes that the important consideration when determining the relaxation of shot peening induced compressive residual stresses under applied load is the way in which the residual and applied stress fields interact. There is clear evidence in the literature that in unnotched samples loaded uniaxially beyond the yield point, the compressive residual stresses resulting from shot peening tend to be significantly reduced by the relaxation process. ${ }^{17}$ In this loading configuration, the maximum relaxation typically occurs in the loading direction, with less significant relaxation in the transverse direction. ${ }^{18,21}$

In our previous work, ${ }^{25}$ the residual stresses in shot peened U-notched samples loaded in three point bend were studied both parallel and perpendicular to loading before fatigue; after one fatigue cycle and at half the fatigue life at a surface strain range of $1.1 \%$. It was found that the residual stresses were relaxed in the perpendicular direction after one fatigue cycle whilst being retained in the loading direction. This was considered to be a result of the unloading process from high tensile stresses in only the near surface region and constraint from lower regions acting in an analogous manner to the original shot peening process. Furthermore, it was found that there was no significant logarithmic relaxation with continuing cycling in this material.

Since the stress distribution in the PBB samples sits somewhat in-between that of the Unotched sample and the equivalent uniaxial sample, it is likely that the residual stresses in the PBB geometry have relaxed more than those in the U-notched geometry, especially given that the high stresses in the PBB sample extend beyond the limit of the compressive residual stress region previously identified as extending to around $300 \mu \mathrm{m} .{ }^{25}$ This observation goes 
some way to explaining the retention of the beneficial effects of shot peening in the Unotched sample at strain ranges where for the PBB sample the benefit is lost.

Whilst surface roughness is known to be detrimental in terms of fatigue life, ${ }^{2}$ the effect is often not considered as important as the effect of work hardening and compressive residual stresses. ${ }^{5}$ In contrast to work which reports an improvement in initiation life, ${ }^{6}$ it has also been previously reported that after peening processes that result in severe surface deformation, the initiation life may be reduced as a result of surface folding resulting from the shot peening acting as stress raising features. ${ }^{4}$ This effect would be expected to be most significant in $\mathrm{HCF}$ since LCF is typically propagation dominated. It would also be reasonable to conclude that the initiation life is a result of the complex combination of surface geometry and strain hardening effects resulting from a given peening process. Furthermore, roughness effects may become more significant if residual stresses are relaxed during operational loading. The present results tend to indicate that even a moderate peening process which is typically applied to industrial components can result in very small non-propagating cracks which may begin to propagate after a certain fraction of life under given loading conditions. Given the lack of any residual stress relaxation in the present system at a point corresponding to the beginning of crack propagation, the propagation from pre-existing cracks cannot be linked to the relaxation of residual stresses as was previously suggested by de los Rios et al.. ${ }^{6}$

It is thus important to note that the improvement of fatigue life is not simply dependent on the magnitude of the compressive residual stress induced by the shot peening process but also on the inter-relationship between the surface conditions created by shot peening, including surface roughness and the work hardened layer. The pre-existing cracks observed in the shot peened notch root appear to be linked to surface roughness induced by the peening process. As mentioned previously, the compressive residual stress produced in these samples extends to approximately $300 \mu \mathrm{m}$ below the surface; the very high stresses were found to extend to around $150 \mu \mathrm{m}$. Indeed the work hardened material would also be expected to extend to depths of $150 \mu \mathrm{m}$ based on the relationship between local microstructural misorientation (used as an indicator of work hardening) and residual stresses shown by Child et al.. ${ }^{27}$

This indicates that the pre-existing cracks on the shot peened surface are likely to be contained within the expected work hardened region, further complicating the analysis of short crack behaviour. The initial non-propagation may be a result of the reduced mean stress as a result of superposition of applied and residual stresses and of the work hardening present in the material, which is typically considered to act mainly in increasing initiation life. In this paper, "initiation" time is considered to be the point at which the non-propagating cracks begin to grow; this clear definition of initiation is often not specified despite the significant impact on the damage tolerant fatigue lifing procedure in which initiation time is typically ignored and cracks of length equivalent to the NDT in use are assumed present. For example, in unpeened turbine fir tree interface geometries, eddy current arrays have been successfully developed to detect cracks of $0.2 \mathrm{~mm}$ depth, with the anticipation that with the correct calibration this could be extended to peened interfaces and crack depths of $0.1 \mathrm{~mm} .^{28}$ 
The subsequent slower crack growth observed in the shot peened samples is thought to be primarily a result of the crack growing through the region containing compressive residual stresses which are generally considered to be the main cause of crack growth retardation. ${ }^{1 \text {, }}$ ${ }^{9}$ Compared to the ground sample behaviour it is clearly the early stages of crack growth which have been slowed in the shot peened samples. The total surface crack length in the shot peened case has to reach $300-400 \mu \mathrm{m}$ before $\mathrm{d} c / \mathrm{d} N$ levels start to match those observed in the ground samples. This correlates to an expected crack depth of around 250-300 $\mu \mathrm{m}$ i.e. the point where the crack may be expected to escape the region of very high compressive residual stresses.

\section{Summary and Conclusions}

In plain bend bars the beneficial effects of shot peening on fatigue life are lost at very high stresses, where significant yielding occurs and the favourable compressive residual stresses are largely relaxed. It is also clear that any lips that form due to shot peening causing local plastic deformation of the surface counteract the benefits of shot peening to some extent because of the gross stress concentration feature produced. The efficacy of shot peening in a notch loaded in bend, appears to be retained to high strain/stress levels, indicating that the relaxation of beneficial compressive stresses at the notch root has not occurred to any significant extent in this highly constrained geometry (as shown experimentally in ${ }^{25}$ ). This geometry has service relevance to turbine blade loading conditions.

Short fatigue crack growth analyses were conducted on both shot peened and ground samples with a stress concentration feature. Under similar applied notch root strain ranges, the shot peened sample exhibits better fatigue resistance than the ground sample. Evidence has been presented for small pre-existing cracks on the shot peened surface, which only started to grow at around $10 \sim 25 \%$ of the fatigue life. At this stage the crack propagation rate was lower than for the ground sample, until the depth of the crack exceeded the expected depth of the significant compressive residual stress field/work hardened region. Once the crack depth exceeded the compressive residual stress region, crack growth rates accelerated to be consistent with those observed in the ground case.

The shot peening benefit has here been linked to the retention of the compressive residual stress and slower crack growth through this region. The possible effects of work hardening and residual stress have not been fully elucidated; however it is clear that the initiation time is the result of the complex interaction between surface geometrical features and work hardening effects. Hence in this case "initiation" can be considered the point at which such cracks start to grow. Future work will evaluate how much of the extended life can be linked to changes in work hardening level and how much to residual compressive stress and how this changes depending on the local stress and strain conditions.

\section{Acknowledgements}


Financial support from the Engineering and Physical Sciences Research Council, E.ON New Build and Technology Ltd., the Royal Commission for the Exhibition of 1851 and China Scholarship Council (CSC) is gratefully acknowledged. Thanks should also be extended to Victoria Sisson and Daniel Bray, students at the University of Southampton, for their assistance in collecting plain bend bar fatigue life data.

\section{References}

1. K. A. Soady, Submitted to Materials Science and Technology, 2012.

2. ESDU: '74027 - The Effect of Surface Roughness on the Fatigue Limit of Steels at Zero Mean Stress', 1974.

3. J. K. Li, Y. Mei, W. Duo, and W. Renzhi, Fatigue and Fracture of Engineering Materials and Structures, 1992, 15(12), 1271 - 1279.

4. Y. Mutoh, G. H. Fair, B. Noble, and R. B. Waterhouse, Fatigue and Fracture of Engineering Materials and Structures, 1987, 10(4), 261 - 272.

5. W. Koster: 'Effect of Residual Stress on Fatigue of Structural Alloys', 3rd International Conference on Practical Application of Residual Stress Technology, Indianapolis, Indiana, USA, 1991, ASM, 1 - 9.

6. E. R. De los Rios, A. Walley, M. T. Milan, and G. Hammersley, Int. J. Fatigue, 1995, 17(7), 493499.

7. Y. K. Gao and X. R. Wu, Acta Mater., 2011, 59, 3737 - 3747.

8. I. Altenberger, B. Scholtes, U. Martin, and H. Oettel, Materials Science and Engineering A, 1999, 264, 1 - 16.

9. L. Wagner: 'Effect of Mechanical Surface Treatments on Fatigue Performance of Titanium Alloys', fatigue Behaviour of Titanium Alloys, Warrendale, PA, 1999, TMS, 253 - 265.

10. G. A. Webster, Int. J. Fatigue, 2001, 23, S375 - S383.

11. M. N. James, D. J. Hughes, Z. Chen, H. Lombard, D. G. Hattingh, D. Asquith, J. R. Yates, and P. J. Webster, Engineering Failure Analysis, 2007, 14, 284 - 395.

12. M. Guagliano and L. Vergani, Eng. Fract. Mech., 2004, 71, 501- 512.

13. A. M. Eleiche, M. M. Megahed, and N. M. Abd-Allah, Journal of Materials Processing Technology, 2001, 113, 502 - 508.

14. S. Suresh and R. O. Ritchie, International Materials Reviews, 1984, 29(1), 445-475.

15. N. E. Dowling, Fatigue \& Fracture of Engineering Materials \& Structures, 1979, 2(2), 129-138.

16. H. T. Pang and P. A. S. Reed, Int. J. Fatigue, 2008, 30(10-11), 2009-2020.

17. R. C. McClung, Fatigue \& Fracture of Engineering Materials \& Structures, 2007, 30(3), 173-205.

18. H. Holzapfel, V. Schulze, $O$. Vöhringer, and E. Macherauch, Materials Science and Engineering: $A, 1998,248(1-2), 9-18$.

19. E. R. De-los-Rios, P. Mercier, and B. M. El-Sehily, Fatigue and Fracture of Engineering Materials and Structures, 1996, 19, $175-184$.

20. W. Z. Zhuang and G. R. Halford, Int. J. Fatigue, 2001, 23, Supplement 1(0), 31-37.

21. S.-B. Kim, E. A., J. Shackleton, G. Bruno, M. Preuss, and P. J. Withers, Metallurgical and Materials Transactions A, 2005, 36A, 3041 - 3053.

22. M. Benedetti, T. Bortolamedi, V. Fontanari, and F. Frendo, Int. J. Fatigue, 2004, 26(8), 889-897.

23. M. Benedetti, V. Fontanari, P. Scardi, C. L. A. Ricardo, and M. Bandini, Int. J. Fatigue, 2009, 31(8-9), 1225-1236.

24. J. Bergstrom and T. Ericsson: 'Relaxation of Shot Peening Induced Compressive Stress During Fatigue of Notched Steel Samples', ICSP-2, Chicago, USA, 1984, 241 - 248.

25. K. A. Soady, B. G. Mellor, J. Shackleton, M. A., and P. A. S. Reed, Materials Science and Engineering A, 2011, 528(29-30), 8579 - 8588.

26. T. Fujita, ISIJ International, 1992, 32, 178-181.

27. D. J. Child, G. D. West, and R. C. Thomson, Acta Mater., 2011, 59(12), 4825-4834.

28. A. Morris, K. A. Soady, and C. Brett, Private Mommunication,E.ON, 2012. 


\section{Captions:}

Figure 1: Sample geometry (in mm) and fatigue test set up (a) U-notch and (b) PBB

Figure 2: FEGSEM (SEI mode) micrograph showing the microstructure of FV448 revealed by Vilella's etch to be tempered martensite

Figure 3: Illustration of shot peened "lips" formed due to surface deformation of plain bend bar samples during the peening process

Figure 4: Strain-life comparison for plain bend bar and U-notched samples in both ground and shot peened conditions

Figure 5 Four cracks were studied in detail in: (a) shot peening sample, (b) ground sample

Figure 6 Fatigue crack length as a function of fatigue life ratio $\mathrm{N}_{\mathrm{i}} / \mathrm{N}_{\mathrm{f}}$ for (a) the shot peened U-notched sample $\left(\mathrm{N}_{\mathrm{f}}=54504\right.$ cycles) and (b) the ground $\mathrm{U}$-notch sample $\left(\mathrm{N}_{\mathrm{f}}=22816\right.$ cycles $)$, under similar applied strain condition $\left(\Delta \varepsilon_{\mathrm{LE} 11}=1.1 \%\right)$

Figure 7 Short crack growth rate as a function of crack length for (a) the shot peened U-notched sample and (b) the ground U-notch under similar applied strain condition $\left(\Delta \varepsilon_{\mathrm{LE} 11}=1.1 \%\right)$

Figure 8 (a) Crack morphology on shot peened surface at different stages of fatigue life; (b) SEM micrograph of a surface short crack initiated from shot peening layers on shot peened notch surface

Figure 9 (a) Crack morphology on ground surface at different stages of fatigue life; (b) SEM micrograph of a crack propagated along the grinding marks

Figure 10 Comparison of stress state between uniaxial, PBB and notched bar samples

Table 1 Compositional analysis (in wt $\%$ ) of FV448 material studied ${ }^{25 .}$

\begin{tabular}{|c|c|c|c|c|c|c|c|c|c|}
\hline Element & $\mathrm{C}$ & $\mathrm{Mn}$ & $\mathrm{Si}$ & $\mathrm{Ni}$ & $\mathrm{Cr}$ & Mo & $\mathrm{V}$ & $\mathrm{Nb}$ & $\mathrm{Fe}$ \\
\hline $\begin{array}{l}\text { Spectrographic analysis } \\
(\mathrm{wt} \%)\end{array}$ & 0.12 & 0.94 & 0.31 & 0.74 & 11.0 & 0.58 & 0.31 & 0.34 & $\mathrm{Bal}$ \\
\hline
\end{tabular}

